\title{
Skeletal Effects of Levothyroxine for Subclinical Hypothyroidism in Older Adults: A TRUST Randomized
}

\section{Trial Nested Study}

Elena Gonzalez Rodriguez, MD, PhD ${ }^{1,2}$, Mirah Stuber ${ }^{3}$, Cinzia Del Giovane, $\mathrm{PhD}^{3}$, Martin Feller, MD, $\mathrm{MSc}^{3,4}$, Tinh-Hai Collet, $\mathrm{MD}^{2}$, Axel L Löwe, $\mathrm{MD}^{3,4}$, Manuel R Blum, MD4, Nicolien A van Vliet, MD ${ }^{5}$, Diana van Heemst, $\mathrm{PhD}^{5}$, Patricia M Kearney, $\mathrm{MD}^{6}$, Jacobijn Gussekloo, MD, PhD7, Simon Mooijaart, MD, Rudi GJ Westendorp, MD, $\mathrm{PhD}^{8}$, David J Stott, $\mathrm{MD}^{9}$, Daniel Aeberli, $\mathrm{MD}^{10}$, Douglas C Bauer, $\mathrm{MD}^{11}$, Didier Hans, $\mathrm{PhD}^{1^{*}}$, Nicolas Rodondi, MD, MAS $\mathrm{S}^{3,4^{*}}$

\section{Affiliations:}

${ }^{1}$ Center of Bone Diseases, Rheumatology Unit, Bone and Joint Department, Lausanne University Hospital and University of Lausanne, Lausanne, Switzerland;

${ }^{2}$ Service of Endocrinology, Diabetes and Metabolism, Department of Medicine, Lausanne University Hospital and University of Lausanne, Lausanne, Switzerland;

${ }^{3}$ Institute of Primary Health Care (BIHAM), University of Bern, Bern, Switzerland;

${ }^{4}$ Department of General Internal Medicine, Inselspital, Bern University Hospital, University of Bern, Bern, Switzerland;

${ }^{5}$ Department of Internal Medicine, section Gerontology and Geriatrics, Leiden University Medical Center, Leiden, The Netherlands

${ }^{6}$ School of Public Health, University College Cork, Cork, Ireland;

${ }^{7}$ Departments of Gerontology and Geriatrics, Leiden University Medical Center, Leiden, Netherlands;

${ }^{8}$ Department of Public Health and Center for Healthy Aging, University of Copenhagen, Copenhagen, Denmark;

${ }^{9}$ Institute of Cardiovascular and Medical Sciences, University of Glasgow, Glasgow, United Kingdom;

(C) Endocrine Society 2019. All rights reserved. For permissions, please e-mail: journals.permissions@oup.com. jc.2019-01572. See endocrine.org/publications for Accepted Manuscript disclaimer and additional information. 
${ }^{10}$ Department of Rheumatology and Clinical Immunology/Allergology, Inselspital, Bern University Hospital, Bern, Switzerland;

${ }^{11}$ Departments of Medicine, Epidemiology and Biostatistics, University of California, San Francisco, USA.

* Didier Hans and Nicolas Rodondi are both equally lead authors for this study.

\section{Corresponding author's contact information and address for requests of reprint:}

Dr Elena Gonzalez Rodriguez

Center of Bone Diseases, Rheumatology Service

CHUV, Lausanne University Hospital

Rue Pierre-Decker 4

Lausanne, $\mathrm{CH}-1011$ Switzerland

Phone: +41213149548

Email: elena.gonzalez-rodriguez@chuv.ch

ORCID (Elena Gonzalez-Rodriguez) ID 0000-0001-6512-6008

Trial registration: The trial was registered on ClinicalTrials.gov numbers NCT01660126 (TRUST Thyroid trial,) and NCT02491008 (Skeletal outcomes).

Funding: The TRUST Thyroid trial was supported by research grant (278148) from the European Union FP7-HEALTH-2011 program and by grants from the Swiss National Science Foundation (SNSF 320030150025 and 320030-172676 to Dr. Rodondi), the Swiss Heart Foundation, and Velux Stiftung (grant 974a to Dr. Rodondi). Dr Collet's research is supported by grants from the Swiss National Science Foundation (PZOOP3-167826). The study medication (levothyroxine and matching placebo) was supplied by Merck KGaA at no cost. Merck played no role in designing, analyzing, or reporting the trial. 
Disclosures: EGR, MS, CDG, MF, THC, ALL, MRB, NAvV, DvH, PMK, JG, SM, RGJW, DJS, DA, DCB and NR have nothing to declare. DH holds stock in Medimaps Group, the makers of the Trabecular Bone Score software. Merck KGaA, Darmstadt, Germany reviewed the manuscript for medical accuracy only before journal submission. The authors are fully responsible for the content of this manuscript, and the views and opinions described in the publication reflect solely those of the authors. 


\section{ABSTRACT (maximum 250 words, actual 249)}

Context: Both thyroid dysfunction and levothyroxine therapy (LT4) have been associated with bone loss, but studies on the effect of LT4 for subclinical hypothyroidism (SHypo) on bone yielded conflicting results.

Objective: To assess the effect of LT4 treatment on bone mineral density (BMD), Trabecular Bone Score (TBS), and bone turnover markers (BTMs) in older adults with SHypo.

Design and Intervention: Planned nested substudy of the double-blind placebo-controlled TRUST trial. Participants with SHypo were randomized to LT4 with dose titration vs. placebo with computerized mock titration.

Setting and Participants: 196 community-dwelling adults over 65 years enrolled at the Swiss TRUST sites had baseline and 1-year follow-up bone examinations; 4 participants withdrew due to adverse events not related to treatment.

Main Outcome Measures: One-year percent changes of BMD, TBS, and two serum BTMs (sCTX and P1NP). Student's t-test for unadjusted analyses, and linear regression adjusted for clinical center and sex, were performed.

Results: Mean age was $74.3 y \pm 5.7,45.4 \%$ were women, and $19.6 \%$ were osteoporotic. The unadjusted 1year change in lumbar spine BMD was similar between LT4 (+0.8\%) and placebo-treated groups (-0.6\%; between-groups difference $+1.4 \%$ : $95 \% \mathrm{Cl}-0.1$ to $2.9, \mathrm{p}=0.059)$. Likewise, there were no between-group differences in 1-year change in TBS $(-1.3 \%$ : $95 \% \mathrm{Cl}-3.1$ to $0.6, \mathrm{p}=0.19)$, total hip $\mathrm{BMD}(-0.2 \%: 95 \% \mathrm{Cl}-1.1$ to $0.1, p=0.61$ ), or BTMs levels ( $\mathrm{sCTX}+24.1 \%: 95 \% \mathrm{Cl}-7.9$ to $56.2, \mathrm{p}=0.14$ ), or after adjustment for clinical centers and sex.

Conclusions: Over one-year levothyroxine had no effect on bone health in older adults with SHypo.

Registration: ClinicalTrial.gov NCT01660126 and NCT02491008

Key words: Subclinical hypothyroidism, Levothyroxine, Bone mineral density, Trabecular Bone Score, Bone markers 
Précis:

One year of levothyroxine for older adults with subclinical hypothyroidism does not affect bone health, as determined by bone mineral density, Trabecular Bone Score, or bone turnover markers. 


\section{Introduction}

The prevalence of subclinical hypothyroidism (SHypo), defined as an elevated thyrotropin (TSH) level with free thyroxine (FT4) within the reference range, increases with age, reaching $>10 \%$ in men over 65 years and up to $21 \%$ in women $\geq 75$ years [1, 2]. Increasing evidence suggests that treating SHypo with levothyroxine (LT4) does not confer clinical benefit $[3,4]$. Although recent UK guidelines recommend against LT4 therapy except in very specific clinical conditions [5], others propose LT4 for adults with SHypo and a TSH $>10.0 \mathrm{mIU} / \mathrm{L}[6,7]$ and up to nine out of ten women with SHypo and a TSH concentration between 5.5 and $10 \mathrm{mIU} / \mathrm{L}$ should be treated if some of these guidelines were followed [8].

The deleterious effect of high thyroid function on bone, even at high-normal levels $[9,10]$ is well established. On the contrary, studies have found no association between SHypo and bone mineral density (BMD) changes [11, 12]; a meta-analysis of individual participant data found no association between SHypo and fracture risk [10]. Concerns have been raised on the impact of LT4 on bone [13], but data on the effects of LT4 replacement on bone in SHypo are scarce and conflicting. Three small ( $n=17$ to 66 ) randomized clinical trials (RCT) showed either no difference $[14,15]$, or a small yet not clinically significant bone loss in the LT4-treated group [16]. Only one RCT analyzed bone turnover markers (BTMs) which increased transiently at 24 weeks in the LT4-treated group (between $7.7 \%$ for alkaline phosphatase, and $29.9 \%$ for SCTX), during a 48 weeks treatment with LT4 [16]. No study has analyzed the effect of levothyroxine substitution on Trabecular Bone Score, a textural index that evaluates pixel gray-level variations in the lumbar spine DXA image and provides an indirect index of trabecular microarchitecture, independent of bone density [17].

The Thyroid Hormone Replacement for Untreated Older Adults with Subclinical Hypothyroidism (TRUST) trial was a multicenter, international, double-blind parallel-group RCT of LT4 versus placebo $[4,18]$ and showed no apparent benefits of treatment on either primary objectives (Hypothyroid Symptoms or 
Tiredness score) or secondary outcomes. Since there was scarce evidence on the effect of SHypo treatment by LT4 on bone health, we measured BMD, TBS and BTM in participants in Swiss centers, at baseline and follow-up of the TRUST trial to assess the effect of LT4 on bone.

\section{Methods}

\section{Study population}

This nested study focused on skeletal outcomes of participants in the Swiss centers (Bern and Lausanne) of the TRUST trial (clinicaltrials.gov NCT02491008, NCT01660126) [4, 18]. It included community-dwelling individuals aged $\geq 65$ years with persistent SHypo. Briefly as previously described [4], persistent SHypo was diagnosed by elevated TSH levels ( $\geq 4.6$ and $\leq 19.9 \mathrm{mIU} / \mathrm{L}$ ) on at least two measurements at least three months apart, and FT4 levels within the assay reference range. Exclusion criteria included use of LT4, antithyroid, amiodarone or lithium treatment within 12 months, thyroid surgery or radio-iodine, severe acute comorbidities, dementia, terminal illness or galactose intolerance [4]. For this bone study, among the 217 participants of the TRUST trial in Switzerland, 21 participants lacked measurements at 1-year follow-up. Four participants withdrew due to adverse events not related to treatment: three on the treatment arm, and one on the placebo arm. This analysis focused on the 196 participants who had baseline and 1-year follow-up DXA and/or BTMs values. Of these, 79 had no DXA exam at baseline or 1year, so there were 117 participants left with both DXA exams (Figure 1). Of the 196 participants, 6 had no BTMs measures at either baseline or 1-year follow-up for technical reasons, so 190 BTMs (sCTX and P1NP) were available for analysis.

The trial was approved by the local Institutional Review Boards, and written, informed consent was obtained from all participants. The trial was conducted in accordance with the principles of the Declaration of Helsinki and Good Clinical Practice guidelines. 


\section{Intervention}

Briefly as previously described [4], treatment started with LT4 50 micrograms daily (25 micrograms in individuals $<50 \mathrm{Kg}$ body weight or with known coronary heart disease). Dose was titrated in the active treatment group according to target TSH levels $\geq 0.4$ and $<4.6 \mathrm{mIU} / \mathrm{L}$ and a computerized mock titration in the placebo group.

\section{Clinical data}

We recorded baseline age, sex, current smoking and alcohol consumption, history of osteoporosis and diabetes mellitus, and all ongoing treatments. Bone-affecting treatments were classified in two categories. Beneficial treatments included anti-osteoporotics (raloxifene, bisphosphonates, denosumab or teriparatide), hormonal replacement therapy, and hydrochlorothiazide. Deleterious bone treatments included systemic or topical glucocorticoids, proton pump inhibitors, aromatase inhibitors, serotonin recapture inhibitors, and antiepileptic treatments. Incident fractures were prospectively recorded.

\section{$B M D$ and TBS measures}

Participants had serial BMD and TBS measurements by dual energy X-ray absorptiometry (DXA) on a GEHCLunar Prodigy (GEHC, Madison, WI, USA) at the Bern study site, and on a GEHC-Lunar iDXA (GEHC, Madison, WI, USA) at the Lausanne site. The two machines were cross-calibrated at the beginning of the trial for both BMD and TBS using the appropriate phantom, and benefited of a daily on-site quality control with the dedicated phantom supplied by the manufacturer. No statistical differences were observed between the two DXA machines; no longitudinal changes were observed during the study period. BMD measures Least Significant Change (LSC) values are: (i) for the GEHC-Lunar Prodigy, $0.030 \mathrm{~g} / \mathrm{cm}^{2}$ at the lumbar spine (L1-L4) and $0.018 \mathrm{~g} / \mathrm{cm}^{2}$ at the total hip; (ii) for the GEHC-Lunar iDXA, $0.028 \mathrm{~g} / \mathrm{cm}^{2}$ at the lumbar spine (L1L4) and $0.033 \mathrm{~g} / \mathrm{cm}^{2}$ at the total hip. Manufacturer recommendations were followed for DXA scans at 
baseline and follow-up; quality assurance review was performed centrally at Lausanne for both the BMD and TBS parameters. BMD was measured at the lumbar spine (antero-posterior projection of L1 through L4) and the proximal femur (neck and trochanteric regions). Recorded images were reanalyzed for 5 individuals because there were inconsistencies within vertebral readings. Individual vertebrae were excluded if there were fractures or degenerative changes, in accordance with the ISCD rules for excluding individual vertebrae [19] and if considered outliers (T-score $\geq+3.0$ SD). The same vertebrae were excluded at different time points, and mean lumbar spine T-score was calculated as the mean of the included vertebra T-score values. Participants were excluded if only one vertebra remained for analysis. TBS of the spine was centrally assessed at Lausanne Center (blinded from clinical outcomes) with a modified version of TBS iNsight v3.0 which accounts for tissue thickness (Medimaps group, Geneva, CH) by Lausanne Center. Region of interest for TBS were (i) all vertebrae, because TBS is minimally affected by degenerative changes [20], and (ii) the same region used for spine BMD (e.g., the same included/excluded vertebrae). TBS LSC is 3.88\%. Left femur measurements were used unless precluded by prosthetic material.

Bone turnover markers (BTMs) measurements

Venous blood was drawn at any time during the day and without regard to fasting status. The Bern University Hospital routine laboratory quantified serum concentration of bone biomarkers Procollagen type $1 \mathrm{~N}$-terminal Polypeptide (P1NP), representing bone formation, and CrossLaps (sCTX), representing bone resorption, in blood samples at baseline and at 1-year follow-up using Roche Cobas $\subset$ technology, from fresh samples (Bern participants) or from frozen samples (Lausanne participants).

\section{Statistical analysis}

We calculated we would need to include 375 participants to detect a difference in the change in total hip BMD as small as $1.3 \%$ over two years between groups, with power of $80 \%$ and two-sided alpha of 0.05 , based on the annual bone loss observed in placebo treated individuals in several US trials [21]. 
Descriptive results (baseline data) are expressed as number of participants (percentage) or as mean \pm standard deviation (SD). Between-group comparisons on the difference between 1-year follow-up and baseline values were performed using Student's t-test for non-adjusted analyses, and linear regression adjusted for clinical site and sex to account for BMD differences resulting from DXA machines and gender, but unadjusted results were similar. Results are expressed as mean percent changes $(95 \%$ confidence interval, $95 \% \mathrm{Cl}$ ). Statistical significance was considered for $p$-values $<0.05$. All analyses were performed using Stata version 15 (StataCorp, College Station, TX) for Windows.

\section{Results}

The mean age at inclusion was $74.3 \pm 5.7$ years, $45.4 \%$ were women, and participants presented with a mean BMI of $27.5 \pm 5.0 \mathrm{~kg} / \mathrm{m}^{2}$ (Table 1). TSH was $6.4 \pm 2.0 \mathrm{mlU} / \mathrm{L}$ and FT4 $13.6 \pm 1.9 \mathrm{pmol} / \mathrm{L}$ before randomization, corresponding to SHypo, which evolved to the euthyroid state at 1 year in the treatment arm but not in the placebo group (TSH $3.2 \pm 1.5$ vs. $5.6 \pm 2.4 ; p<0.001$ ). The characteristics of the 117 participants with DXA exams are detailed by treatment group in Supplementary Table 1 [22]. At the baseline DXA exam, $19.6 \%$ of the participants were osteoporotic, and $20.5 \%$ were osteopenic according to the WHO definition based on the lowest T-score from lumbar spine, total hip or femoral neck [23]. Mean T-scores values were in the normal range at lumbar spine $(-0.6 \pm 1.5 \mathrm{SD})$ and total hip $(-0.6 \pm 1.2 \mathrm{SD})$, and in the osteopenic range at the femoral neck $(-1.1 \pm 1.1 \mathrm{SD})$. On the other hand, $26.5 \%$ had degraded TBS and $29.1 \%$ had partially degraded TBS, according to the thresholds defined in McCloskey et al [24]. The distribution of all parameters was balanced between groups (all p-values $>0.10$ ) both in the whole study group and the DXA data subgroup, except for deleterious treatments (including systemic or topic glucocorticoids, proton pump inhibitors, aromatase inhibitors, serotonin recapture inhibitors, and antiepileptic treatments) in the DXA data subgroup, which were more frequent in LT4 treated participants (40.7\%, vs. $22.4 \%$ of placebo treated participants, $p$-value $=0.03)$. 
Table 2 shows BMD and TBS values at baseline and 1-year follow-up by treatment group. One left femur value outlier due to femur anomalies was replaced by right femur readings; femur values were excluded for one participant as it was measured on different sides at each exam. Three participants had no hip image because of bilateral total hip prosthesis. At baseline, BMD in the placebo group was $1.122 \pm 0.204$ $\mathrm{g} / \mathrm{cm}^{2}, 0.963 \pm 0.166 \mathrm{~g} / \mathrm{cm}^{2}$ and $0.890 \pm 0.131 \mathrm{~g} / \mathrm{cm}^{2}$ in lumbar spine, total hip and femoral neck respectively, and $1.133 \pm 0.150 \mathrm{~g} / \mathrm{cm}^{2}, 0.980 \pm 0.167 \mathrm{~g} / \mathrm{cm}^{2}, 0.908 \pm 0.160 \mathrm{~g} / \mathrm{cm}^{2}$ in the same sites in the LT4 treated group. At baseline, lumbar spine TBS was $1.325 \pm 0.113$ in the placebo group vs. $1.307 \pm 0.968$ in the LT4 treated group.

BMD percentage changes after one year were not statistically different in placebo and LT4-treated participants in non-adjusted analyses (Table 2, Figure 2) at lumbar spine BMD (-0.6\% vs.+0.8\%; between group difference $+1.4 \%$ : $95 \% \mathrm{Cl}-0.1$ to $2.9, \mathrm{p}=0.059)$. Likewise, there were no between-group differences in 1-year change in total hip BMD $(-0.2 \%$ : $95 \% \mathrm{Cl}-1.1$ to $0.1, \mathrm{p}=0.61)$ or femoral neck $\mathrm{BMD}(-0.2 \%: 95 \% \mathrm{Cl}$ 1.8 to $1.4, p=0.82$ ). Further adjustment for center and sex did not change the results (Supplementary Table 2 [22]). Unadjusted lumbar spine TBS percentage changes after one year were not statistically different between the two groups either $(-1.3 \%: 95 \% \mathrm{Cl}-3.1$ to $0.6, \mathrm{p}=0.19)$. We found similar results for TBS both in adjusted analyses, and independently of the included vertebrae (all vertebrae, or only those included in BMD analysis after application of ISCD guidelines). Results were similar after excluding participants receiving bone-affecting treatments.

We assessed the effect of LT4 treatment vs placebo on BTMs: There was no statistically significant difference between groups, either in unadjusted (Table 3), or adjusted analyses (Supplementary Table 2 [22]). The results were similar in sensitivity analyses by clinical site, or after excluding participants who were receiving bone affecting treatments (data not shown).

In each group, 3 fractures were observed during follow-up, with no significant difference between groups. 


\section{Discussion}

Our study did not show any harmful effect of LT4 replacement for one year on bone health, which we assessed by measuring BMD, TBS and BTMs in community-dwelling adults aged $\geq 65$ with SHypo. Our study is the largest randomized controlled trial for SHypo treatment to date, and no other study has analyzed SHypo treatment effect on bone microarchitecture as assessed by lumbar spine TBS.

Three earlier RCTs analyzed the effect of LT4 treatment of SHypo in bone with conflicting results. Similar to our study, a double-blinded ( $n=31,75 \%$ women, mean age: 68 years, follow-up 10 months) [14], and an unblinded ( $n=17$ post-menopausal women, follow-up 14 months) [15] RCT did not find a significant difference in BMD change between LT4 and placebo treated individuals. Meta-analyses on the association of SHypo with fracture risk $[10,12]$ or BMD $[11,12]$ showed no difference in observed results when they included or excluded LT4-treated individuals, but did not analyze outcomes specifically in this group. Only the double-blinded RCT by Meier et al. reported a statistically but not clinically significant BMD loss [16] at the lumbar spine when it compared treatment to placebo $(-1.15 \%)$ in 66 women (56.1 years, follow-up 48 weeks). In this study TSH at follow-up $(3.1 \pm, 0.3 \mathrm{mU} / \mathrm{L})$ was similar to that of our study $(3.2 \pm 1.5 \mathrm{mU} / \mathrm{L})$ but was higher at baseline (12.8 $\pm 1.4 \mathrm{mU} / \mathrm{L}$, as compared to $6.3 \pm 1.9)$; a stronger change in TSH could explain the observed results. Of note, $74 \%$ were postmenopausal; $37 \%$ of these women were on hormone replacement therapy (HRT), but interaction with estrogens was not analyzed. The transient increase in BTMs in the study by Meier et al. [16] may indicate that LT4 treatment restored bone turnover to the usual early menopause values in these almost two decades younger participants. Pines et al. reported that the beneficial effects of estrogen replacement on BMD were reduced when it was combined with LT4 replacement therapy [25]. In our study, participants were older than in the Jaeschke et al. RCT [14], under half were women, and very few participants were on HRT (less than 6.9\%) so we could not conduct a separate analysis. Adjustment by sex did not change the magnitude or the statistical significance of the 
effect. Our results thus accord with those of two studies with a similar population $[14,15]$, suggesting LT4 treatment for SHypo does not harm bone health after one year of treatment in individuals over 65; the current study results may however not apply to a younger population.

Only three studies analyzed the effect of thyroid function on TBS. In two prospective cohorts of participants with thyroid cancer undergoing TSH suppressive therapy for 5 to 10 years [26, 27], excess LT4 treatment had a deleterious effect on TBS only in women transitioning from pre- to post-menopause [26], and no effect in post-menopausal women at treatment initiation [26, 27]. But in a euthyroid cohort [28] high-normal free T4 levels, but not TSH values, were associated with low TBS only in post-menopausal women. In our study, as published, TBS changes are not associated to TSH values changes; the link to free T4 cannot be analyzed in detail, as it was not measured at follow-up.

Our conclusions are reinforced by the absence of a significant difference in BTMs changes between both groups at one year. Meier et al. [16] obtained similar results by measuring different BTMs, including sCTX, finding no changes at 48 weeks. They did observe a transient increase (at 24 weeks) in treated adults, which they interpreted as restoration of normal remodeling levels that had been decreased in SHypo. We did not have earlier BTMs measures to evaluate this hypothesis.

The greatest strengths of our trial were its double-blind RCT design and that it was the biggest RCT on SHypo and bone (past ones $n=17$ to 66 ). Among limitations, it may still be underpowered because we were able to include only 196 individuals. However, the point estimates in the current results went in the opposite direction to published ones, with a non-significant BMD increase under LT4 and a slight decrease under placebo, which makes it unlikely that we would have found different results with a larger sample. This trend for an eventual benefit of LT4 treatment on lumbar spine ( $p=0.06$ for the difference in adjusted analysis) is most probably due to chance. Also the largest change included in the $95 \%$ confidence intervals is a gain of $2.9 \%$ spine BMD, or a loss of $4.0 \%$ for TBS, which makes it very unlikely that we have missed a 
clinically important difference. We might have been limited by the short follow-up period, although it was the longest blinded trial. Our study cannot address with appropriate power the effect in participants with more pronounced subclinical hypothyroidism, due to the low number of participants with TSH > $10 \mathrm{mUI} / \mathrm{L}$, although this is also the case in the general population [1]. In our study TSH target values were $<4.6 \mathrm{mU} / \mathrm{L}$ as proposed for older persons [29], with some different expert opinions [7], and we cannot exclude that attaining lower TSH values might have a deleterious effect on bone health. Lumbar spine BMD baseline values were quite high in our participants, suggesting underlying degenerative changes that may interfere with the measures. However, degenerative changes do not affect femoral measures, neither lumbar spine TBS, which give similar results. Finally, SCTX pre-analytical conditions were not standardized (not done fasting in the morning) explaining the large range, but P1NP, which does not depend on these preanalytical conditions, did not change neither over time nor depending on treatment, confirming the absence of LT4 effect on remodeling at 1-year follow-up.

Our results are reassuring in the context of the large number of individuals with SHypo treated with LT4, although this trend may change in the view of latest evidence and guidelines [5]. Only a large long-term, placebo-controlled trial will definitively determine if treatment of SHypo adversely affects bone health, and to the best of our knowledge such a trial is not ongoing or planned in the near future. Until long-term safety is ascertained, we suggest that physicians who wish to treat SHypo in their older patients prescribe the lowest thyroxine dose to achieve a clinical response and keep TSH within the normal range. 


\section{References}

1. Canaris, GJ, Manowitz, NR, Mayor, G and Ridgway, EC The Colorado thyroid disease prevalence study. Arch Intern Med. 2000;160(4):526-534

2. Hollowell, JG, Staehling, NW, Flanders, WD, Hannon, WH, Gunter, EW, Spencer, CA, and Braverman, LE Serum TSH, T(4), and thyroid antibodies in the United States population (1988 to 1994): National Health and Nutrition Examination Survey (NHANES III). J Clin Endocrinol Metab. 2002;87(2):489499

3. Feller, M, Snel, M, Moutzouri, E, Bauer, DC, de Montmollin, M, Aujesky, D, Ford, I, Gussekloo, J, Kearney, PM, Mooijaart, S, Quinn, T, Stott, D, Westendorp, R, Rodondi, N, and Dekkers, OM Association of Thyroid Hormone Therapy With Quality of Life and Thyroid-Related Symptoms in Patients With Subclinical Hypothyroidism: A Systematic Review and Meta-analysis. JAMA. 2018;320(13):1349-1359

4. Stott, DJ, Rodondi, N, Kearney, PM, Ford, I, Westendorp, RGJ, Mooijaart, SP, Sattar, N, Aubert, CE, Aujesky, D, Bauer, DC, Baumgartner, C, Blum, MR, Browne, JP, Byrne, S, Collet, TH, Dekkers, OM, den Elzen, WPJ, Du Puy, RS, Ellis, G, Feller, M, Floriani, C, Hendry, K, Hurley, C, Jukema, JW, Kean, S, Kelly, M, Krebs, D, Langhorne, P, McCarthy, G, McCarthy, V, McConnachie, A, McDade, M, Messow, M, O'Flynn, A, O'Riordan, D, Poortvliet, RKE, Quinn, TJ, Russell, A, Sinnott, C, Smit, JWA, Van Dorland, HA, Walsh, KA, Walsh, EK, Watt, T, Wilson, R, Gussekloo, J, and Group, TS Thyroid Hormone Therapy for Older Adults with Subclinical Hypothyroidism. N Engl J Med. 2017;376(26):2534-2544

5. Bekkering, GE, Agoritsas, T, Lytvyn, L, Heen, AF, Feller, M, Moutzouri, E, Abdulazeem, H, Aertgeerts, B, Beecher, D, Brito, JP, Farhoumand, PD, Singh Ospina, N, Rodondi, N, van Driel, M, Wallace, E, Snel, M, Okwen, PM, Siemieniuk, R, Vandvik, PO, Kuijpers, T, and Vermandere, M Thyroid hormones treatment for subclinical hypothyroidism: a clinical practice guideline. BMJ. 2019;365(I2006 
6. Garber, JR, Cobin, RH, Gharib, H, Hennessey, JV, Klein, I, Mechanick, JI, Pessah-Pollack, R, Singer, PA, Woeber, KA, American Association Of Clinical, E, and American Thyroid Association Taskforce On Hypothyroidism In, A Clinical practice guidelines for hypothyroidism in adults: cosponsored by the American Association of Clinical Endocrinologists and the American Thyroid Association. Thyroid. 2012;22(12):1200-1235

7. Pearce, SH, Brabant, G, Duntas, LH, Monzani, F, Peeters, RP, Razvi, S, and Wemeau, JL 2013 ETA Guideline: Management of Subclinical Hypothyroidism. Eur Thyroid J. 2013;2(4):215-228

8. Rodriguez-Gutierrez, R, Maraka, S, Ospina, NS, Montori, VM, and Brito, JP Levothyroxine overuse: time for an about face? Lancet Diabetes Endocrinol. 2017;5(4):246-248

9. Aubert, CE, Floriani, C, Bauer, DC, da Costa, BR, Segna, D, Blum, MR, Collet, TH, Fink, HA, Cappola, AR, Syrogiannouli, L, Peeters, RP, Asvold, BO, den Elzen, WPJ, Luben, RN, Bremner, AP, Gogakos, A, Eastell, R, Kearney, PM, Hoff, M, Le Blanc, E, Ceresini, G, Rivadeneira, F, Uitterlinden, AG, Khaw, KT, Langhammer, A, Stott, DJ, Westendorp, RGJ, Ferrucci, L, Williams, GR, Gussekloo, J, Walsh, JP, Aujesky, D, Rodondi, N, and Thyroid Studies, C Thyroid Function Tests in the Reference Range and Fracture: Individual Participant Analysis of Prospective Cohorts. J Clin Endocrinol Metab. 2017;102(8):2719-2728

10. Blum, MR, Bauer, DC, Collet, TH, Fink, HA, Cappola, AR, da Costa, BR, Wirth, CD, Peeters, RP, Asvold, BO, den Elzen, WP, Luben, RN, Imaizumi, M, Bremner, AP, Gogakos, A, Eastell, R, Kearney, PM, Strotmeyer, ES, Wallace, ER, Hoff, M, Ceresini, G, Rivadeneira, F, Uitterlinden, AG, Stott, DJ, Westendorp, RG, Khaw, KT, Langhammer, A, Ferrucci, L, Gussekloo, J, Williams, GR, Walsh, JP, Juni, P, Aujesky, D, Rodondi, N, and Thyroid Studies, C Subclinical thyroid dysfunction and fracture risk: a meta-analysis. JAMA. 2015;313(20):2055-2065 
11. Segna, D, Bauer, DC, Feller, M, Schneider, C, Fink, HA, Aubert, CE, Collet, TH, da Costa, BR, Fischer, K, Peeters, RP, Cappola, AR, Blum, MR, van Dorland, HA, Robbins, J, Naylor, K, Eastell, R, Uitterlinden, AG, Rivadeneira Ramirez, F, Gogakos, A, Gussekloo, J, Williams, GR, Schwartz, A, Cauley, JA, Aujesky, DA, Bischoff-Ferrari, HA, Rodondi, N, and Thyroid Studies, C Association between subclinical thyroid dysfunction and change in bone mineral density in prospective cohorts. J Intern Med. 2018;283(1):56-72

12. Yang, R, Yao, L, Fang, Y, Sun, J, Guo, T, Yang, K, and Tian, L The relationship between subclinical thyroid dysfunction and the risk of fracture or low bone mineral density: a systematic review and metaanalysis of cohort studies. J Bone Miner Metab. 2018;36(2):209-220

13. Viniol, A, Hickstein, L, Walker, J, Donner-Banzhoff, N, Baum, E, and Becker, A Influence of thyroid hormone therapy on the fracture rate - A claims data cohort study. Bone. 2016;86(86-90

14. Jaeschke, R, Guyatt, G, Gerstein, H, Patterson, C, Molloy, W, Cook, D, Harper, S, Griffith, L, and Carbotte, R Does treatment with L-thyroxine influence health status in middle-aged and older adults with subclinical hypothyroidism? J Gen Intern Med. 1996;11(12):744-749

15. Ross, DS Bone density is not reduced during the short-term administration of levothyroxine to postmenopausal women with subclinical hypothyroidism: a randomized, prospective study. Am J Med. $1993 ; 95(4): 385-388$

16. Meier, C, Beat, M, Guglielmetti, M, Christ-Crain, M, Staub, JJ, and Kraenzlin, M Restoration of euthyroidism accelerates bone turnover in patients with subclinical hypothyroidism: a randomized controlled trial. Osteoporos Int. 2004;15(3):209-216

17. Shevroja, E, Lamy, O, Kohlmeier, L, Koromani, F, Rivadeneira, F, and Hans, D Use of Trabecular Bone Score (TBS) as a Complementary Approach to Dual-energy X-ray Absorptiometry (DXA) for Fracture Risk Assessment in Clinical Practice. J Clin Densitom. 2017;20(3):334-345 
18. Stott, DJ, Gussekloo, J, Kearney, PM, Rodondi, N, Westendorp, RG, Mooijaart, S, Kean, S, Quinn, TJ, Sattar, N, Hendry, K, Du Puy, R, Den Elzen, WP, Poortvliet, RK, Smit, JW, Jukema, JW, Dekkers, OM, Blum, M, Collet, TH, McCarthy, V, Hurley, C, Byrne, S, Browne, J, Watt, T, Bauer, D, and Ford, I Study protocol; Thyroid hormone Replacement for Untreated older adults with Subclinical hypothyroidism - a randomised placebo controlled Trial (TRUST). BMC Endocr Disord. 2017;17(1):6

19. Hans, D, Downs, RW, Jr., Duboeuf, F, Greenspan, S, Jankowski, LG, Kiebzak, GM, Petak, SM, and International Society for Clinical, D Skeletal sites for osteoporosis diagnosis: the 2005 ISCD Official Positions. J Clin Densitom. 2006;9(1):15-21

20. Padlina, I, Gonzalez-Rodriguez, E, Hans, D, Metzger, M, Stoll, D, Aubry-Rozier, B, and Lamy, O The lumbar spine age-related degenerative disease influences the BMD not the TBS: the Osteolaus cohort. Osteoporos Int. 2017;28(3):909-915

21. Black, DM, Thompson, DE, Bauer, DC, Ensrud, K, Musliner, T, Hochberg, MC, Nevitt, MC, Suryawanshi, S, Cummings, SR, and Fracture Intervention, T Fracture risk reduction with alendronate in women with osteoporosis: the Fracture Intervention Trial. FIT Research Group. J Clin Endocrinol Metab. 2000;85(11):4118-4124

22. Gonzalez Rodriguez, E, Stuber, M, Del Giovane, C, Feller, M, Collet, TH, Löwe, AL, Blum, MR, van Vliet, NA, van Heemst, D, Kearney, P, Gussekloo, J, Mooijaart, SP, Westendorp, RGJ, Stott, DJ, Aeberli, D, Bauer, D, Hans, D, and Rodondi, N, Skeletal Effects of Levothyroxine for Subclinical Hypothyroidism in Older Adults: A TRUST Randomized Trial Nested Study. Zenodo 2019. Deposited 19 August 2019. http://doi.org/10.5281/zenodo.3370733

23. Kanis, JA Assessment of fracture risk and its application to screening for postmenopausal osteoporosis: synopsis of a WHO report. WHO Study Group. Osteoporos Int. 1994;4(6):368-381 
24. McCloskey, EV, Oden, A, Harvey, NC, Leslie, WD, Hans, D, Johansson, H, Barkmann, R, Boutroy, S, Brown, J, Chapurlat, R, Elders, PJM, Fujita, Y, Gluer, CC, Goltzman, D, Iki, M, Karlsson, M, Kindmark, A, Kotowicz, M, Kurumatani, N, Kwok, T, Lamy, O, Leung, J, Lippuner, K, Ljunggren, O, Lorentzon, M, Mellstrom, D, Merlijn, T, Oei, L, Ohlsson, C, Pasco, JA, Rivadeneira, F, Rosengren, B, Sornay-Rendu, E, Szulc, P, Tamaki, J, and Kanis, JA A Meta-Analysis of Trabecular Bone Score in Fracture Risk Prediction and Its Relationship to FRAX. J Bone Miner Res. 2016;31(5):940-948

25. Pines, A, Dotan, I, Tabori, U, Villa, Y, Mijatovic, V, Levo, Y, and Ayalon, D L-thyroxine prevents the bone-conserving effect of HRT in postmenopausal women with subclinical hypothyroidism. Gynecol Endocrinol. 1999;13(3):196-201

26. De Mingo Dominguez, ML, Guadalix Iglesias, S, Martin-Arriscado Arroba, C, Lopez Alvarez, B, Martinez Diaz-Guerra, G, Martinez-Pueyo, Jl, Ferrero Herrero, E, and Hawkins Carranza, F Low trabecular bone score in postmenopausal women with differentiated thyroid carcinoma after long-term TSH suppressive therapy. Endocrine. 2018;62(1):166-173

27. Kim, EH, Jeon, YK, Pak, K, Kim, IJ, Kim, SJ, Shin, S, Kim, BH, Kim, SS, Lee, BJ, Lee, JG, Goh, TS, and Kim, K Effects of Thyrotropin Suppression on Bone Health in Menopausal Women with Total Thyroidectomy. J Bone Metab. 2019;26(1):31-38

28. Hwangbo, Y, Kim, JH, Kim, SW, Park, YJ, Park, DJ, Kim, SY, Shin, CS, and Cho, NH High-normal free thyroxine levels are associated with low trabecular bone scores in euthyroid postmenopausal women. Osteoporos Int. 2016;27(2):457-462

29. Javed, Z and Sathyapalan, T Levothyroxine treatment of mild subclinical hypothyroidism: a review of potential risks and benefits. Ther Adv Endocrinol Metab. 2016;7(1):12-23 
Figure 1: Flowchart of the nested TRUST bone study

(Footnotes):

FU: follow-up. AE: adverse events. DXA: Dual-X-ray-Absorptiometry. ISCD: International Society for Clinical Densitometry. BTMs: Bone Turnover Markers.

Figure 2: One year change in BMD (bone mineral density, left) at LS (lumbar spine, continuous line), TH (total hip, dotted line) and FN (femoral neck, broken line), in placebo (diamonds) and LT4 (cross) treated patients. 
Table 1: Characteristics of included participants, by treatment group

\begin{tabular}{|c|c|c|}
\hline & Placebo & LT4 treated \\
\hline Sample size & 96 & 100 \\
\hline Bern study site & $71(74)$ & $74(74)$ \\
\hline Female & $44(45.8)$ & $45(45)$ \\
\hline Age (years) & $74.2 \pm 6.1$ & $74.3 \pm 5.3$ \\
\hline Weight (kg) & $75.0 \pm 14.8$ & $78.2 \pm 17.4$ \\
\hline Height (cm) & $166.5 \pm 8.9$ & $167.1 \pm 8.6$ \\
\hline $\mathrm{BMI}\left(\mathrm{kg} / \mathrm{m}^{2}\right)$ & $27.0 \pm 4.5$ & $27.9 \pm 5.3$ \\
\hline Current smoking & $8(8.3)$ & $8(8.0)$ \\
\hline Excess alcohol consumption & $11(11.5)$ & $8(8.0)$ \\
\hline \multicolumn{3}{|l|}{ TSH (mUl/L) } \\
\hline Baseline & $6.5 \pm 2.2$ & $6.3 \pm 1.9$ \\
\hline Median (IQR) & $5.7(5.2-7.1)$ & $5.8(5.1-6.8)$ \\
\hline Range & $4.6-17.0$ & $4.6-16.8$ \\
\hline Free T4 (pmol/L) & $13.7 \pm 1.8$ & $13.5 \pm 2.0$ \\
\hline $\mathrm{GFR}<30 \mathrm{ml} / \mathrm{min}$ & $3(3.1)$ & $3(3.0)$ \\
\hline Osteoporosis history & $13(13.5)$ & $13(13.3)$ \\
\hline Diabetes history & $10(10.4)$ & $16(16.0)$ \\
\hline Ca supplemented & $24(25.0)$ & $18(18.0)$ \\
\hline Vitamin D supplemented & $23(24.0)$ & $32(32.0)$ \\
\hline \multicolumn{3}{|l|}{ Bone affecting treatments } \\
\hline Anti-osteoporotic or HRT & $11(11.5)$ & $5(5.0)$ \\
\hline HTZC & $12(12.5)$ & $11(11.0)$ \\
\hline Systemic GC & $3(3.1)$ & $2(2.0)$ \\
\hline Deleterious & $28(29.2)$ & $40(40.0)$ \\
\hline
\end{tabular}

LT4: Levothyroxine. BMI: body mass index. Excess alcohol consumption: more than 2 units per day. Ca: calcium. Anti-osteoporotic treatments: raloxifen, bisphosphonates, denosumab or teriparatide. HRT: hormonal replacement therapy. HTZC: hydrochlorothiazide. GC: glucocorticoids. Deleterious: proton 
pump inhibitors, systemic or topic glucocorticoids, aromatase inhibitors, serotonin recapture inhibitors, antiepileptic treatments. Results are expressed as mean \pm standard deviation for continuous variables and as number of participants (percentage) for categorical variables. 
Table 2: BMD $\left(\mathrm{g} / \mathrm{cm}^{2}\right)$ and TBS values, and percentage changes after one year of treatment, by treatment group.

\begin{tabular}{|c|c|c|c|c|}
\hline & Placebo & LT4 treated & $\begin{array}{l}\text { LT4 treated vs. } \\
\text { Placebo }\end{array}$ & p-value \\
\hline Lumbar spine, sample size & 53 & 52 & & \\
\hline \multicolumn{5}{|l|}{ BMD } \\
\hline Baseline $\left(\mathrm{g} / \mathrm{cm}^{2}\right)$ & $1.122 \pm 0.204$ & $1.133 \pm 0.150$ & & \\
\hline 1-year follow-up $\left(\mathrm{g} / \mathrm{cm}^{2}\right)$ & $1.115 \pm 0.206$ & $1.140 \pm 0.145$ & & \\
\hline $\begin{array}{l}\text { Changes after one year } \\
\text { treatment, non-adjusted (\%) }\end{array}$ & $-0.6(-1.8$ to 0.6$)$ & $0.8(-0.1$ to 1.7$)$ & $1.4(-0.1$ to 2.9$)$ & 0.059 \\
\hline \multicolumn{5}{|l|}{ TBS } \\
\hline Baseline (unitless) & $1.325 \pm 0.113$ & $1.307 \pm 0.968$ & & \\
\hline 1-year follow-up (unitless) & $1.331 \pm 0.098$ & $1.299 \pm 0.108$ & & \\
\hline $\begin{array}{l}\text { Changes after one year } \\
\text { treatment, non-adjusted (\%) }\end{array}$ & $0.7(-0.6$ to 2.1$)$ & $-0.5(-1.9$ to 0.8$)$ & $-1.3(-3.1$ to 0.6$)$ & 0.19 \\
\hline Femur, sample size & 57 & 56 & & \\
\hline \multicolumn{5}{|l|}{ Total hip } \\
\hline Baseline $\left(\mathrm{g} / \mathrm{cm}^{2}\right)$ & $0.963 \pm 0.166$ & $0.980 \pm 0.167$ & & \\
\hline 1-year follow-up $\left(\mathrm{g} / \mathrm{cm}^{2}\right)$ & $0.960 \pm 0.166$ & $0.975 \pm 0.173$ & & \\
\hline $\begin{array}{l}\text { Changes after one year } \\
\text { treatment, non-adjusted (\%) }\end{array}$ & $-0.4(-1$ to 0.3$)$ & $-0.6(-1.2$ to 0.1$)$ & $-0.2(-1.1$ to 0.7$)$ & 0.61 \\
\hline \multicolumn{5}{|l|}{ Femoral neck } \\
\hline Baseline $\left(\mathrm{g} / \mathrm{cm}^{2}\right)$ & $0.890 \pm 0.131$ & $0.908 \pm 0.160$ & & \\
\hline 1-year follow-up $\left(\mathrm{g} / \mathrm{cm}^{2}\right)$ & $0.885 \pm 0.131$ & $0.901 \pm 0.161$ & & \\
\hline $\begin{array}{l}\text { Changes after one year } \\
\text { treatment, non-adjusted (\%) }\end{array}$ & $-0.5(-1.3$ to 0.2$)$ & $-0.7(-2.2$ to 0.7$)$ & $-0.2(-1.8$ to 1.4$)$ & 0.82 \\
\hline
\end{tabular}

LT4: Levothyroxine. PI: placebo. n: sample size. BMD: bone mineral density. TBS: trabecular bone score. Results are expressed as mean BMD/TBS \pm SD, or as mean percentage BMD/TBS change in one year (95\% CI). Between-group comparisons performed using Student's $t$-test. 
Table 3: BTMs values, and non-adjusted percentage changes after one year of treatment, by treatment group.

\begin{tabular}{|c|c|c|c|c|}
\hline & Placebo & LT4 treated & $\begin{array}{l}\text { LT4 treated vs. } \\
\text { Placebo }\end{array}$ & p-value \\
\hline Sample size & 94 & 96 & & \\
\hline \multicolumn{5}{|l|}{ sCTX } \\
\hline Baseline (ng/L) & $247.9 \pm 148.9$ & $244.7 \pm 156.1$ & & \\
\hline 1-year follow-up (ng/L) & $252.0 \pm 166.8$ & $259.3 \pm 149.9$ & & \\
\hline $\begin{array}{l}\text { Changes after one year } \\
\text { treatment }(\%)\end{array}$ & $9.1(-1.7$ to 19.9$)$ & $\begin{array}{c}33.2(3.1 \text { to } \\
63.3)\end{array}$ & $\begin{array}{c}24.1(-7.9 \text { to } \\
56.2)\end{array}$ & 0.14 \\
\hline \multicolumn{5}{|l|}{ P1NP } \\
\hline Baseline $(\mu \mathrm{g} / \mathrm{L})$ & $39.5 \pm 15.9$ & $40.0 \pm 25.1$ & & \\
\hline 1-year follow-up ( $\mu \mathrm{g} / \mathrm{L})$ & $39.1 \pm 17.9$ & $41.8 \pm 22.8$ & & \\
\hline $\begin{array}{l}\text { Changes after one year } \\
\text { treatment }(\%)\end{array}$ & $2.3(-4.1$ to 8.8$)$ & 10.7 (3 to 18.3 ) & 8.3 (-1.6 to 18.3$)$ & 0.10 \\
\hline
\end{tabular}

BTMs: bone turnover markers. LT4: Levothyroxine. PI: placebo. SCTX: serum C-terminal Crosslinked Telopeptides. P1NP: Procollagen Type $1 \mathrm{~N}$-terminal Propeptide. Results are expressed as mean sCTX/P1NP $\pm \mathrm{SD}$, or as mean percentage sCTX/P1NP change in one year $(95 \% \mathrm{Cl})$. Between-group comparisons performed using Student's $t$-test. 
Figure 1

No DXA follow-up at 1 year:

Bern $(n=66)$

Lausanne $(n=13)$

-46 no DXA exams* $\quad-7$ no DXA exams*

- 19 only 2 years FU

-6 only 2 years FU

1 technical issue

*enrolled before bone substudy, home visits, refusal

Others:

- Lack hip DXA: no hip DXA image $(n=3)$, different hip at baseline and FU $(n=1)$

- All vertebra excluded following ISCD guidelines $(n=12)$

196 included participants:

145 at Bern site

51 at Lausanne site

21 excluded participants:

Lost to FU ( $n=2)$

- Death $(n=2)$

Withdrawal $(n=12 ; 4$ for $A E)$

- No FU clinical data at 1 year $(n=5)$

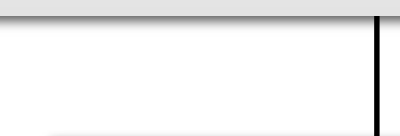

117 DXA exams baseline and 1 year FU

113 hip analysis

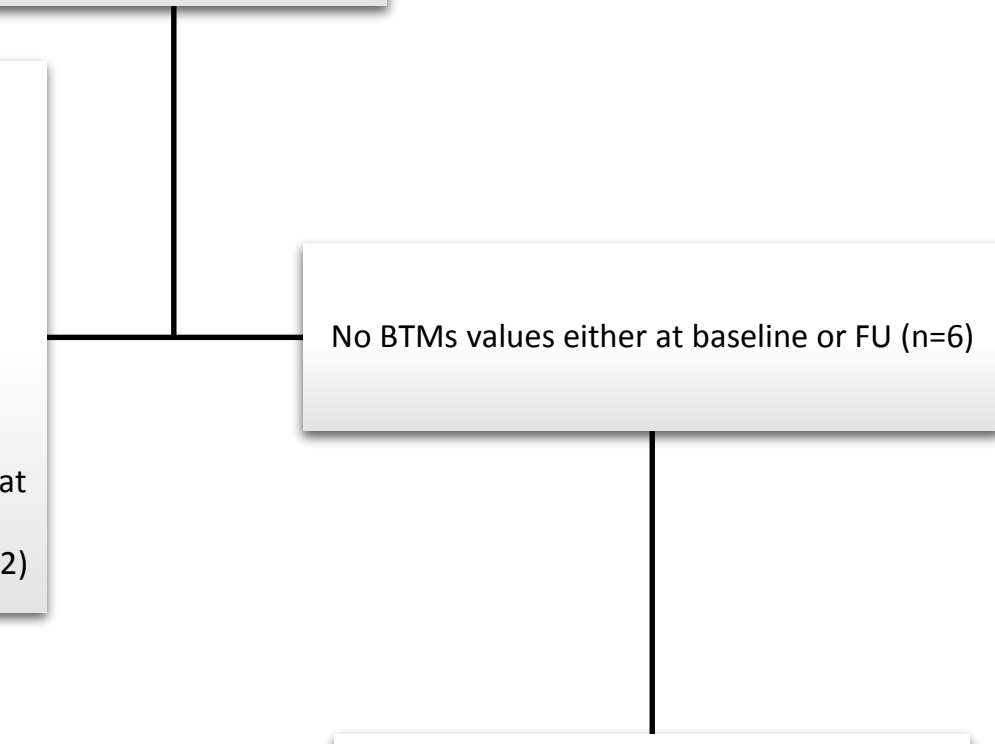

105 vertebrae analysis 
Figure 2

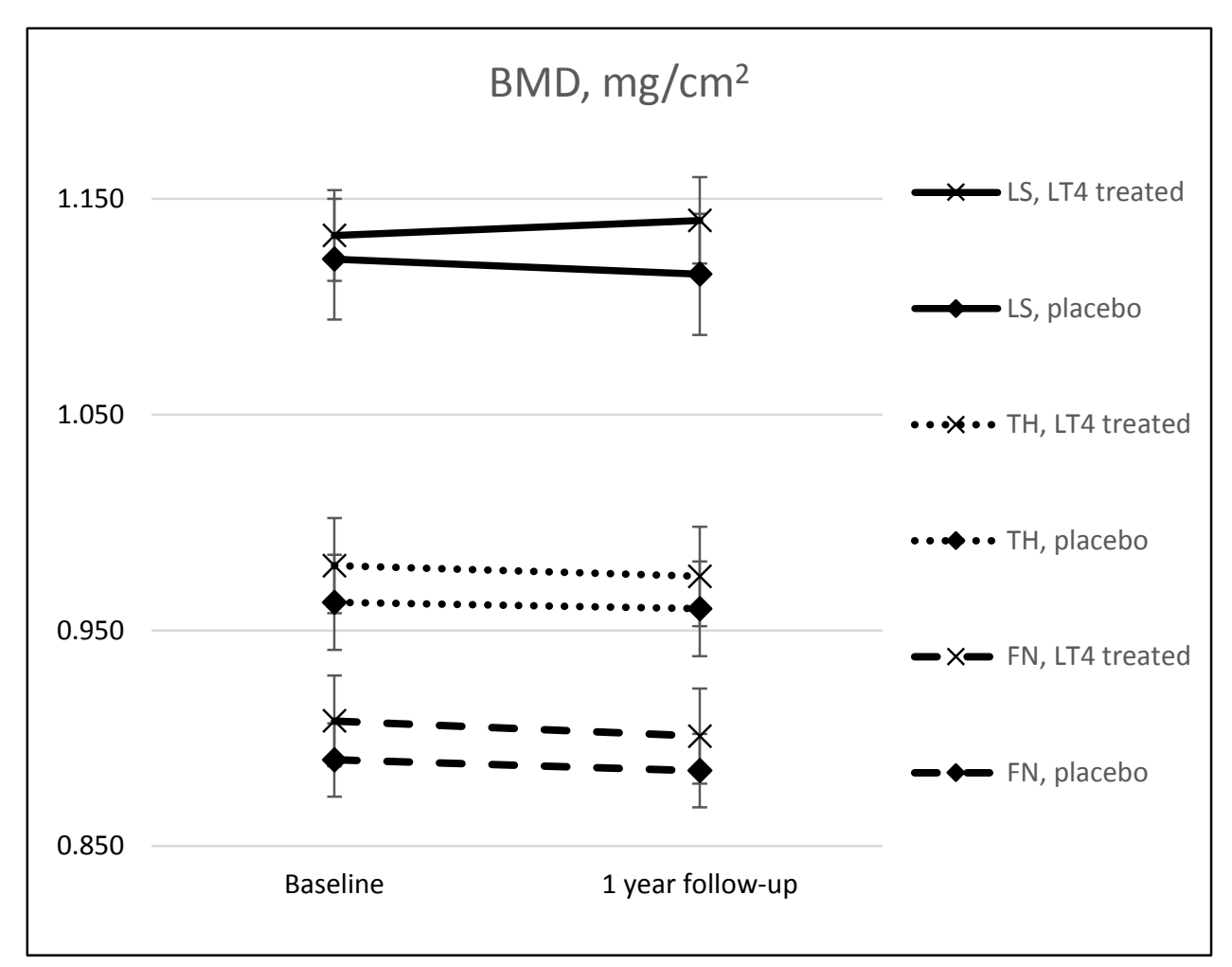

